\title{
DESCRIPTION OF TWO NEW SPECIES OF HAPLACARUS (ACARI: ORIBATEI) FROM MALABAR, KERALA, INDIA
}

\author{
Alphonsa Xavier ${ }^{1}$, M.A. Haq ${ }^{2}$ and N. Ramani ${ }^{3}$ \\ ${ }^{1}$ Department of Zoology, Government Arts \& Science College, Calicut, Kerala 673018, India \\ ${ }^{2,3}$ Department of Zoology, University of Calicut, Calicut, Kerala 673635, India \\ Email: ${ }^{1}$ puthusery@sify.com; ${ }^{2}$ haqma@sancharnet.in
}

\begin{abstract}
Two new species of Haplacarus viz., $\mathrm{H}$. xavieri and $\mathrm{H}$. davisi belonging to the family Lohmanniidae are described from Malabar, Kerala

KEYWORDS

Haplacarus davisi $s p$. nov., Haplacarus xavieri $s p$. nov., Kerala, Malabar, new species, Oribatid mites, soil

\section{Abbreviations}

ro - rostral seta; le - lamellar seta; exa - anterior exobothridial seta; exp - posterior exobothridial seta; in - interlamellar seta; bo - bothridium; ss - sensillus
\end{abstract}

An extensive survey on the oribatid fauna of Malabar revealed the occurrence of several new species, of which a few are found potential in terms of biodegradation of higher plant residues. In the present paper two new species of the genus Haplacarus, are described.

The genus Haplacarus is characterised by genital plates without transverse suture, preanal plate broad, anal and adanal plates fused, one pair of anal and four pairs of adanal setae and notogastral and epimeral region without neotrichy.

The type materials are housed at the Division of Acarology, Department of Zoology, University of Calicut, Kerala, India.

All measurements are given in $\mathrm{mm}$.

\section{Haplacarus xavieri sp. nov.} (Figs. 1-7)

\section{Material Examined}

Holotype: Female, 24.viii.2001, soil and leaf litter from Botanical Garden, Calicut University, Kerala, India, coll. Alphonsa Xavier. Paratype: Two females, one male, same information as holotype.

\section{Etymology}

Species is named in honour of P.L. Xavier, the father of the first author.

\section{Diagnostic characters}

Colour: Pale yellow to light brown

Measurements: Length: 552 (Range 545-564); Width: 288 (Range 280-294)

Dorsal Region (Fig. 1): Body elongated with conical anterior and posterior ends. Microsulpture of the integument in the form of uniformly distributed papillae and fine punctations.
Prodorsum: Anterior margin of the rostrum smooth and entire without incision. All prodorsal setae foliate and weakly serrated. Seta $r o$ inserted well behind the anterior tip of rostrum, directed forward and measures 74. Seta le inserted below the level of ro outwardly inserted and 72 long. Seta exa curved at the base and measures 92. Seta exp directed posteriorly and measures 72. Seta in inserted very close to $b o$ and measures 96. Sensillus pectinate with 14-15 long branches (Fig. 3). A prodorsal band formed of 10-12 papillae extends between the interlamellar setae. The integument of prodorsum exhibits uniformly distributed papillae which become smaller in size towards the tip of rostrum.

Notogaster: Notogaster elongate with straight margins. Nine notogastral bands detected of which $s_{2}, s_{3}, s_{6}, s_{8}$ and $s_{9}$ incomplete towards the centre. Sixteen pairs of notogastral setae, all foliate and weakly serrate. Microsculpture of notogaster consists of small knob-like papillae distributed uniformly except along the notogastral bands

Ventral Region (Fig. 2): Rutellum (Fig. 2) well developed with 23 prominent knobs towards the tip. Chelicerae (Fig. 5) sclerotised moderately, digitus mobilis with two and digitus fixus with three teeth. Setae $c h a$ and $c h b$ smooth. Pedipalp (Fig. 6) with a chaetotaxy of 0-0-1-0-9. Infracapitulum with four pairs of setae. Setae $a$ and $m_{1}$ smooth and simple, while $h$ and $m_{2}$ barbed. Epimeral setal formula 3-1-3-4. Antero-lateral margin of genital plate bordered by triangular aggenital plate. Genital plate without transverse suture. Ten setae on each genital plate, four antiaxial and six paraxial in position. Paraxial setae thin, small and smooth, antiaxial setae long, slightly barbed. Preanal plate broad with centrally downward projection posteriorly. Anal and adanal plates fused, each carrying one anal and four adanal setae. Anal seta located between $a d_{3}$ and $a d_{4}$ much smaller than adanal setae and finely barbed. Adanal setae foliate and barbed. Fissure $i a$, ip and ih clearly visible on lateral sides. A few area porosae distributed on either side of the ventral plate. Ornamentation of ventral region consists of irregularly distributed papillae, smaller than that on the dorsal side.

Legs: All legs monodactylous, chaetotaxy of leg I (Fig. 7) 0-5-54-17. Seta $v$ on femur $I$ highly foliate with midirib and serrate. Setae $b v$ and $d$ smooth. Setae $l$ ' and $l$ "' foliate and serrate. Genu $I$ carries a solenidion $\alpha$. Seta $v$ like that of femur I. Setae $l$ ', $l$ "' and $d$ simple and smooth. Tibia $I$ carries a long solenidion $\varsigma$. Setae $l$ ', l' long, $l$ ' barbed, $x t$ highly foliate and serrate. Tarsus $I$ with two solenidia $w_{1}$ and $w_{2}$. Setae $p v$ ' and $p v$ " small, well foliate and serrate. Seta $m$ long, foliate and serrate. Seta $s$ long and (c) Zoo Outreach Organisation; www.zoosprint.org Manuscript 1302; Received 17 December 2004; Finally accepted 02 July 2005; Date of publication 21 July 2005 

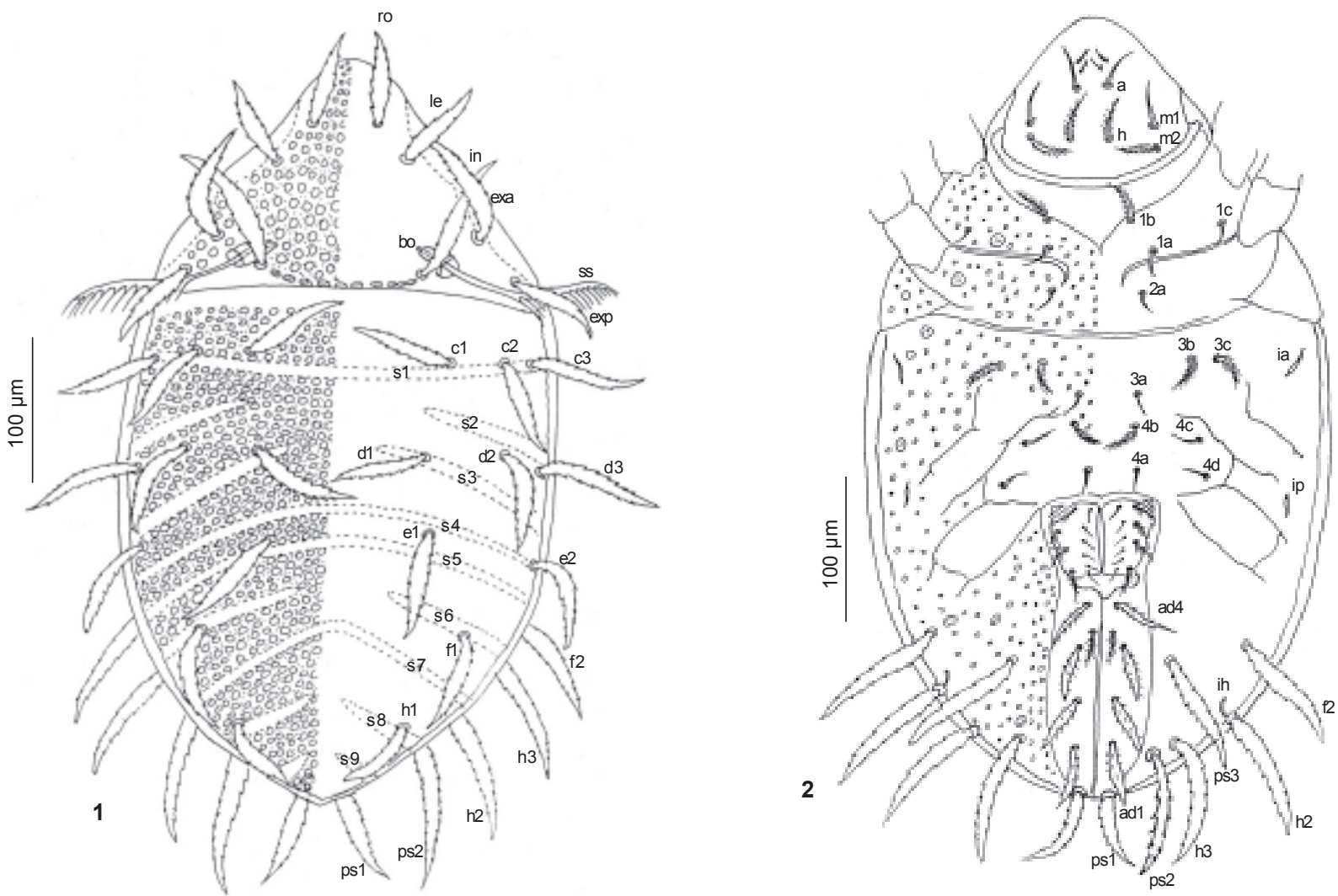

Figures 1-2. Haplacarus xavieri sp. nov.

1 - Dorsal view; 2 - Ventral view
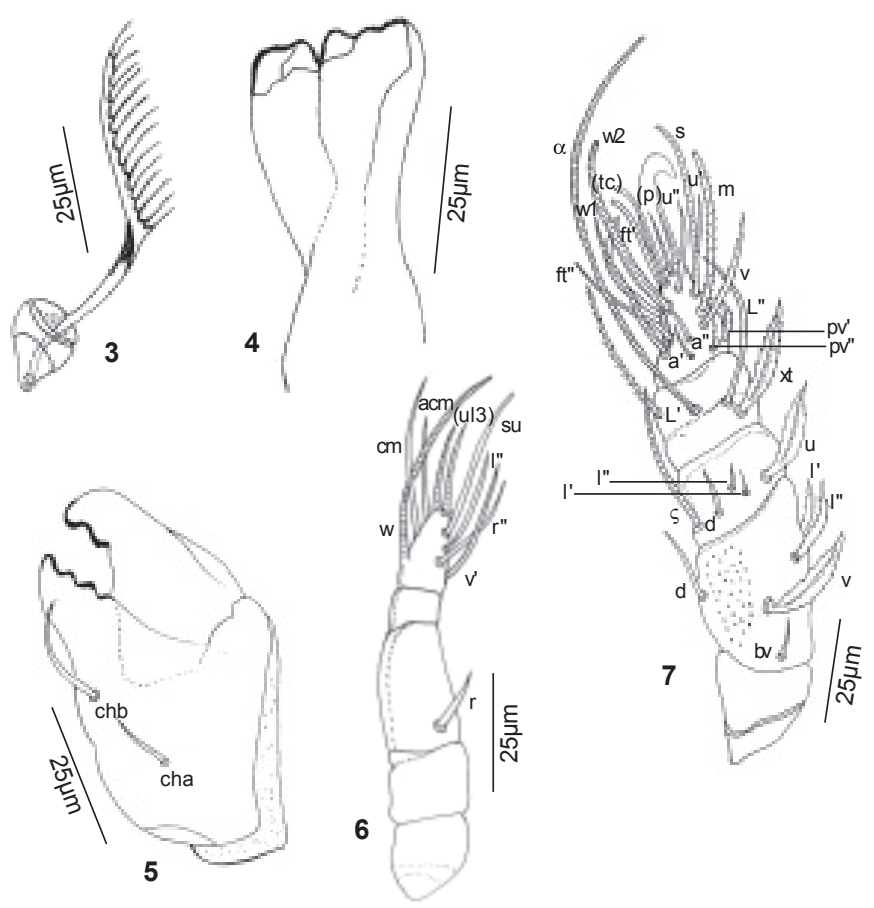

Figure 3-7. Haplacarus xavieri sp. nov.

3 - Sensillus; 4 - Rutellum; 5 - Chelicera;

6 - Pedipalp; 7 - Leg I smooth. Other setae smooth with varying length.

\section{Remarks}

The genus Haplacarus was erected by Wallwork in 1962 with H. foliatus as type species. The genus at present includes 10 species described from different parts of the world. The new species $H$. xavieri on comparison with the previously known species of Haplacarus shows similarity to $H$. porosus described by Haq and Clement (1995). The common morphological features detected are the nature of sensillus, number of notogastral and anal setae. However, the present new species differs from $H$. porosus in the incomplete nature of notogastral bands $s_{2}, s_{3}, s_{6}, s_{8}$, and $s_{9}$ and in the nature of infracapitular and adanal setae, in epimeral setal formula and in the possession of a prodorsal band. The unique features of $H$. xavieri are: (i) Presence of nine notogastral bands of which $s_{2}, S_{3}, s_{6}, s_{8}$, and $s_{9}$ incomplete; (ii) Sensillus with 14-15 branches; (iii) Infracapitular setae $a$ and $m_{1}$ smooth, $h$ and $m_{2}$ barbed; (iv) A prodorsal band formed of 10-12 papillae extends between the interlamellar setae; (v) Epimeral setal formula 3-1-3-4. 


\section{Haplacarus davisi sp. nov.}

(Figs. 8-14)

\section{Material Examined}

Holotype: Female, 28.x.2001, Kakkanchery, leaf litter of Xylea xylocarpa Malappuram, Kerala, India, coll. Alphonsa Xavier. Paratype: Five females, same information as holotype.

\section{Etymology}

Species is named in honour of Dr. Davis Paul, the husband of the first author.

\section{Diagnostic characters}

Colour: Golden brown

Measurements: Length: 553 (Range 540-558); Width: 320 (Range 310-322)

Dorsal Region (Fig 8): Body fairly elongated and flat with conical anterior and rounded posterior ends. Integument with scattered rounded foveolae, which are more recognisable at the prodorsum and posterior region of the notogaster.

Prodorsum: Prodorsum triangular with broad base and conical anterior region. A small conical projection present in the middle of the lateral prodorsal margin. Five pairs of prodorsal setae, smooth and setiform. Seta ro inserted below the tip of rostrum and measures 54. Seta le measures 90 , inserted well below and outer to the level of ro. Seta in originates just below and inner to the level of bo and of same length as le. exa measures 85 and exp 68. ss pectinate with 13-14 branches (Fig. 10). A prodorsal band formed of 6-8 crescentic structures present between the insertional points of setae in. Prodorsal integument ornamented with rounded foveolae which become smaller in size towards the rostral apex.

Notogaster: Notogaster elongated, lateral sides straight and rounded posteriorly. Dorsosejugal suture slightly arched and distinct. Eight notogastral bands formed of closely arranged circular area porosae present. $s_{3}$ and $s_{4}$ fused towards the mid line. Sixteen pairs of notogastral setae, all smooth. Marginal setae longer, range in size 75-82. Central setae smaller and measure 55-66. Notogaster ornamented with rounded foveolae towards lateral and posterior side.

Ventral Region (Fig. 9): Rutellum (Fig. 11) with three prominent blunt teeth. Chelicerae (Fig. 12) stout and well sclerotised. Setae cha long and chb short, both smooth. Pedipalp (Fig. 13) five segmented with a chaetotaxy of 0-1-1-0-9. Infracapitulum with four pairs of smooth setae. Epimeral setal formula 3-1-3-3. All setae smooth. Anterolateral margin of genital plate bordered by triangular aggenital plate. Genital plates without transverse suture and bear four antiaxial and six paraxial setae. Paraxial setae smaller. All setae smooth. Preanal plate broad with a median downward excrescence. Anal and adanal plates fused. Anoadanal setal formula typical of the genus, i.e., 1+4. All setae smooth. Fissure ia located outside sejugal apodeme, ip near the postero-lateral margin of the body. Integument of the ventral region with fine punctations.
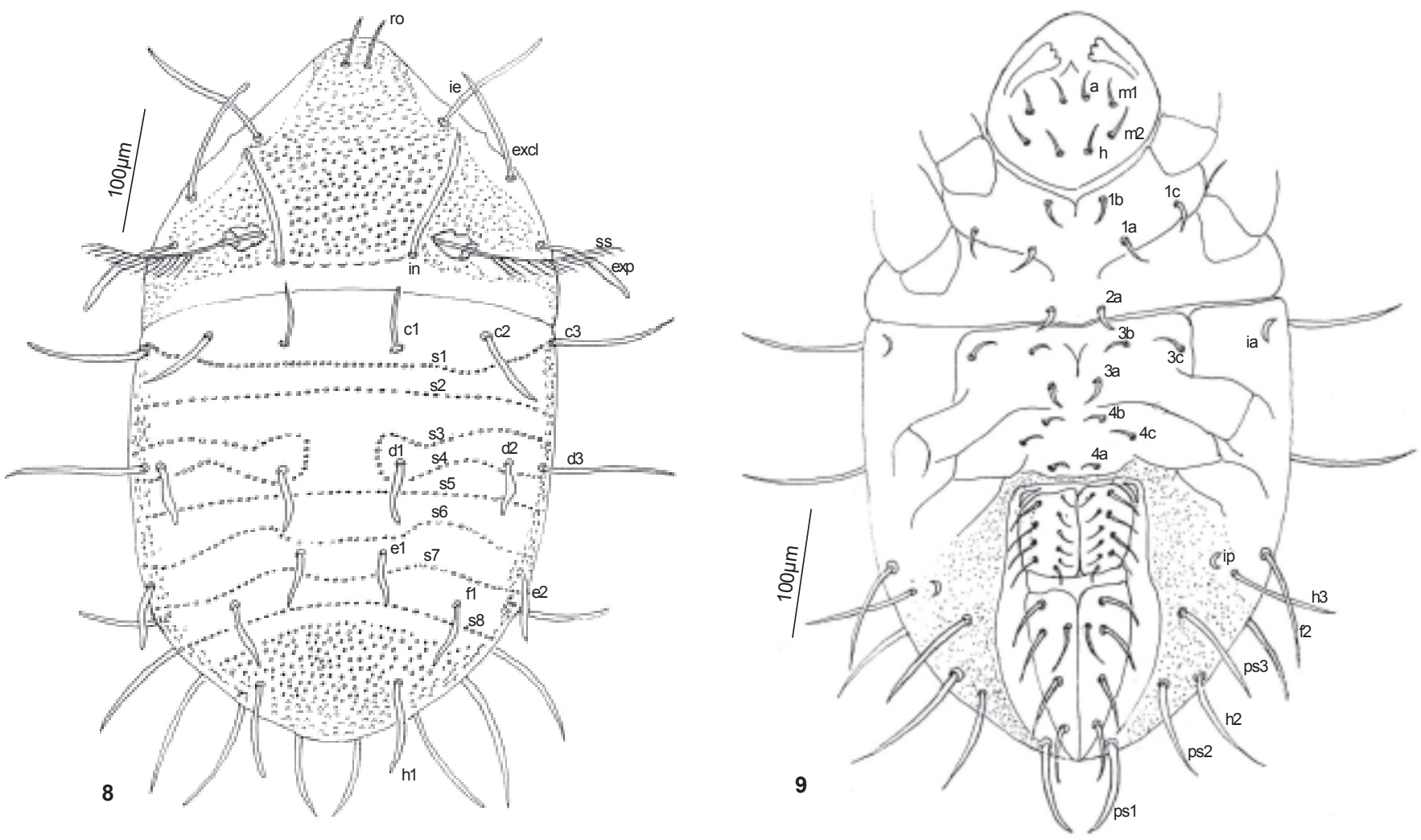

Figures 8-9. Haplacarus davisi sp. nov. 8 - Dorsal view; 9 - Ventral view 

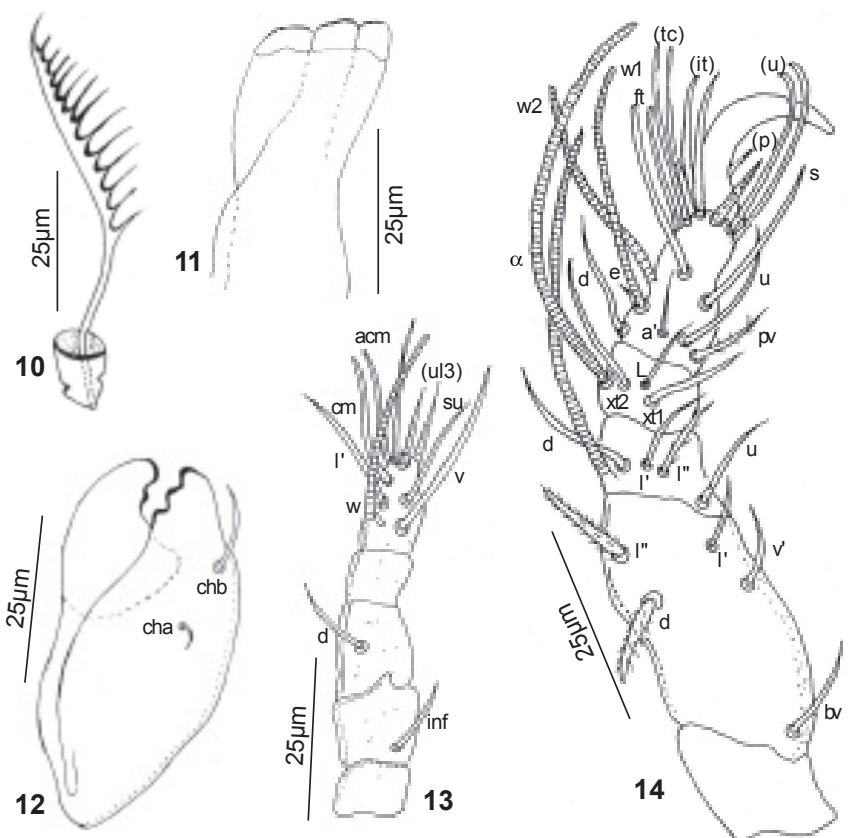

Figures 10-14. Haplacarus davisi sp. nov.

10 - Sensillus; 11 - Rutellum; 12 - Chelicera; 13 - Pedipalp; 14 - Leg 1

Legs

All legs monodactylous. Chaetotaxy of leg I (Fig. 14) 0-5-5-418. Seta $d$ on femur $I$ foliate and barbed. Seta $l$ " stouter and barbed. Setae $b v, v^{\prime}$ and $l$ ' smooth. Genu $I$ bears five setae including solenidion $\alpha$. Seta l'slightly barbed, others smooth. Tibia $I$ carries a long solenidion $j$. Tarsus $I$ with two solenidia viz., $w_{1}$ and $w_{2}$. Seta $p v^{\prime}$ slightly barbed, others smooth.

\section{Remarks}

A comparison of Haplacarus davisi sp. nov. with other described species reveals its similarity with $H$. pairathi Aoki, 1965. Both possess smooth prodorsal, notogastral, infracapitular, anal and adanal setae. But $H$. davisi differs from $H$. pairathi in the number and nature of notogastral bands, lateral prodorsal margin, insertion of seta le, epimeral setal formula and in the presence of a prodorsal band. The unique features of $H$. davisi are: (i) Eight notogastral bands, $s_{3}$ and $s_{4}$ fused; (ii) Insertion of seta le above seta exa.; (iii) Epimeral setal formula 3-1-3-3; (iv) Presence of a prodorsal band formed of 6-8 crescentic structures between setae in.; (v) Sensillus with 13-14 branches.

Described species of the genus Haplacarus

1. H. foliatus Wall work, 1962 - Ghana

2. H. pairathi Aoki, 1965 - Thailand

3. H. bengalensis Bhatacharya, 1974 - India

4. H. javensis Hammer, 1980

5. H. pandanus Sengbusch, 1982 - Micronesia

6. H. keralensis Haq et al., 1984 - India

7. H. maharashtraensis Sanyal, 1984 - India

8. H. bhadurii Sanyal, 1984 - India

9. H. rugosus Mahunka, 1987 - Malaysia
10. H. porosus Haq and Clement, 1987 - India

\section{REFERENCES}

Aoki, J.I. (1965). New oribatiden von den inset sado (Acarina: Oribatei). Japanese Journal of Zoology 14(3): 1-12.

Haq, M.A. and A. Clement (1995). Two new species of Lohmanniid mites (Acari, Oribatei) from Malabar, India. Indian Journal of Acarology, 13(1\&2): 23-28.

Wallwork, J.A. (1962). Some oribatei from Ghana X. The family Lohmanniidae. Acarologia 4(3): 457-487.

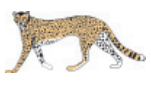

\section{ZSO9
ZOOS' PRINT JOURNAL}

Zoos' Print Journal is the only monthly peer-reviewed wildlife, conservation, taxonomy and veterinary journal in the region and the only journal where the date of publication (usually the 21st of every month) precedes the month of publication.

Average lag time for publication of accepted manuscripts is 60 days. In case of taxonomic papers, it is less than 30 days.

Subscribe to this and encourage interested colleagues and friends to subscribe to Zoos' Print Journal. Recommend your department and university/college libraries to subscribe to this regular monthly journal.

Zoos' Print Journal is indexed / abstracted in BIOSIS/ Biological Abstracts, Zoological Records, Elsevier BIOBASE/ Current Awareness in Biological Sciences, Veterinary Records, Indian Science Abstracts, Index Fungorum, Bibliography of Systematic Mycology, Nutrition and Food Science, Veterinary Science Database, Biology Browser and the following CAB Abstracts: Animal Breeding Abstracts, Ornamental Horticulture, Forestry Abstracts, Tropical Diseases Bulletin, Helminthological Abstracts, Horticultural Science Abstracts, Review of Agricultural Entomology, Agroforestry Abstracts, Review of Aromatic and Medicinal Plants, Veterinary Bulletin, Protozoological Abstracts, Review of Medical and Veterinary Entomology, Review of Medical and Veterinary Mycology, Review of Plant Pathology, World Agricultural and Rural Sociology Abstracts, Abstracts on Hygiene and Communicable Diseases, Index Veterinarius, Plant Breeding Abstracts, Animal Science Database, Grasslands and Forage Abstracts.

\section{ZOOS' PRINT JOURNAL is available online at www.zoosprint.org}

For more details contact:

Sanjay Molur, Editor, Zoos' Print Journal

Zoo Outreach Organisation

29-1 Bharathi Colony, Peelamedu

Coimbatore, Tamil Nadu 641004

India

Ph: +91 422 2568906, 2561087, 2561743

Fx: +914222563269

Email: herpinvert@vsnl.com or editorzpj@rediffmail.com

Or visit us at www.zoosprint.org 